\begin{tabular}{|l|}
\hline Access this article online \\
\hline Quick Response Code: \\
\hline
\end{tabular}

Departments of Pathology and Lab Medicine and ${ }^{1}$ Paediatrics, All India Institute of Medical Sciences, Bhopal, Madhya Pradesh, India

Address for correspondence: Dr. Ujjawal Khurana, Department of Pathology and Lab Medicine, All India Institute of Medical Sciences, Bhopal - 462 020, Madhya Pradesh, India.

E-mail: ujjawal.patho@ aiimsbhopal.edu.in

Submission: 28-09-2018 Accepted: 12-12-2018

\title{
Mucopolysaccharidosis: A case report highlighting hematological aspects of the disease
}

\author{
Rubal Jain, Ujjawal Khurana, Bhavna Dhingra Bhan', Garima Goel, \\ Neelkamal Kapoor
}

\section{Abstract:}

A 11/2-year-old female child presented with swelling in thoracolumbar region and delayed developmental milestones. The routine hemogram analysis on Sysmex XN 1000 showed flags of white blood cell (WBC) abnormal scattergram and lymphocytosis. The peripheral smear examination showed Alder-Reilly (AR) granules leading to a suspicion of underlying Mucopolysaccharidosis (MPS). Further clinical workup, radiographic studies, chemical test lead to the confirmatory diagnosis of MPS. A flag of abnormal WBC scattergram and AR anomaly are the hematological findings that can be seen in a case of MPS.

Key words:

Alder-Reilly anomaly, automated blood counters, mucopolysaccharidosis, Morquio syndrome

\section{Introduction}

$\mathrm{M}$ ucopolysaccharidosis (MPS) are a group of disorders characterized by a genetic defect involving deranged lysosomal degradation of glycosaminoglycans and oligosaccharide chains of glycoproteins and majority of subtypes are being transmitted as autosomal recessive disease. ${ }^{[1]}$ It has a wide syndromic presentation involving skeletal abnormalities, facial dysmorphism, hepatosplenomegaly, neurodevelopmental abnormality, and reduced lifespan. The Alder-Reilly (AR) anomaly on peripheral smear is a known association with MPS. ${ }^{[2,3]}$ However, abnormality of the white blood cell (WBC) scatter plot in these cases has not been reported so far.

\section{Case Report}

A 11/2-year-old female child reported for swelling in thoracolumbar region

This is an open access journal, and articles are distributed under the terms of the Creative Commons Attribution-NonCommercial-ShareAlike 4.0 License, which allows others to remix, tweak, and build upon the work non-commercially, as long as appropriate credit is given and the new creations are licensed under the identical terms.

For reprints contact: reprints@medknow.com and inability to walk and stand without support. She was a firstborn child of nonconsanguineous parents of low socioeconomic status. The clinical examination of the child revealed coarse facies, broad mouth, and short neck with no organomegaly. Initial blood work-up on Sysmex XN 1000 showed a flag of WBC abnormal scattergram and lymphocytosis. The scatter plot on White cell nucleated channel (WNR scattergram) showed an abnormal scatter when compared with normal patients [Figure 1]. Her complete blood count showed a hemoglobin of $111 \mathrm{~g} / \mathrm{l}$, red blood cell count of $4.37 \times 10^{12} / \mathrm{L}$, mean corpuscular volume of $83.1 \mathrm{fl}$, mean corpuscular hemoglobin (MCH) of $25.4 \mathrm{pg}$, $\mathrm{MCH}$ concentration of $30.6 \mathrm{~g} / \mathrm{dl}$, red cell distribution width $14.8 \%$, total WBC count of $14.08 \times 10^{9} / \mathrm{L}$ with lymphocyte predominance (Absolute lymphocyte count: $10.38 \times 10^{9} / \mathrm{L}$ ), platelet count of $242 \times 10^{9} / \mathrm{L}$. On peripheral examination, almost all the neutrophils showed dense blue/purple black granules in the cytoplasm partially obscuring the nucleus; these were

How to cite this article: Jain $\mathrm{R}$, Khurana $\mathrm{U}$, Bhan $\mathrm{BD}$, Goel G, Kapoor N. Mucopolysaccharidosis: A case report highlighting hematological aspects of the disease. J Lab Physicians 2019;11:97-9. 


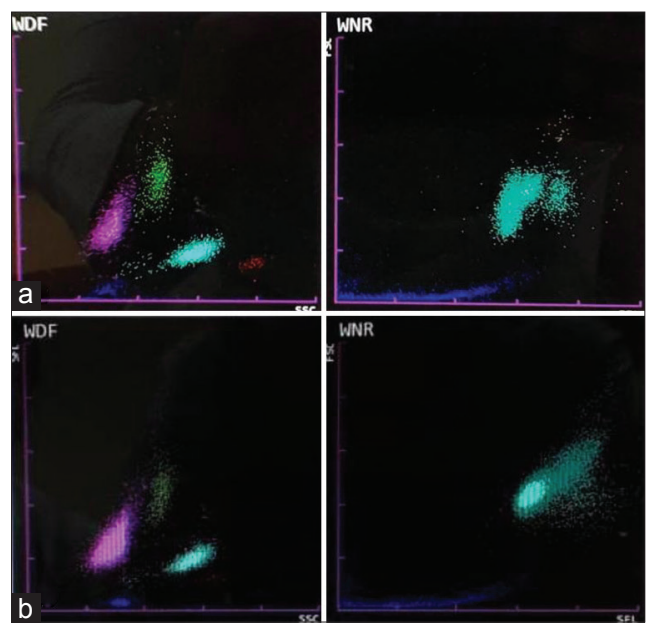

Figure 1: The white blood cell scattergrams (Sysmex XN1000, WDF stands for White cell differential channel, WNR stands for White cell nucleated channel) (a) Normal patient's white blood cell scattergram (b) White blood cell scattergrams of the patient; the WNR scattergrams are abnormal

resembling toxic granulations [Figure $2 \mathrm{c}$ and $\mathrm{d}$ ]. On intricate observation, similar granules although lesser in number were seen in many of the lymphocytes and also were appreciated in an occasional monocyte. The presence of these granules in the leukocytes was raising a suspicion of AR anomaly and underlying MPS. Her ophthalmic examination revealed corneal haziness and mild increase in corneal size. On radiological evaluation, spatula-shaped ribs, tapering of proximal metacarpal, thickening of skull bones with J-shaped sella turcica were also observed [Figure $2 \mathrm{a}$ and $\mathrm{b}$ ]. MPS excretion spot test was positive on the urine sample (Toluidine blue spot test). The indexed patient was suffering from MPS Type IV (Morquio's syndrome). The case describes that abnormal WBC scatter plot on WNR channel and AR granules are the hematological findings that can be seen in a case of MPS.

\section{Discussion}

Automated blood cell counters have revolutionized the blood examination in recent times with newer parameters being explored for their association with various clinical findings and for rendering an appropriate diagnosis. The WBC scatter plot patterns can point to diseases such as malarial infestation, leukemias, promyelocytic leukemia, chronic myeloid leukemia, underlying sepsis, dengue, and presence of oil/liquid fat in the blood. ${ }^{[4,5]}$ The Sysmex $\mathrm{XN}$ series measures WBC parameters with the help of 2 channels White cell differential channel (WDF) and WNR, also a third channel is available which can be used for reflex testing; the WBC progenitor channel WPC. ${ }^{[6]}$ The underlying principles for analyzing WBCs are: Forward scatter which gives information on cell size, side scatter (SSC) which gives information on intracellular structure of cell, and side fluorescence (SFL).

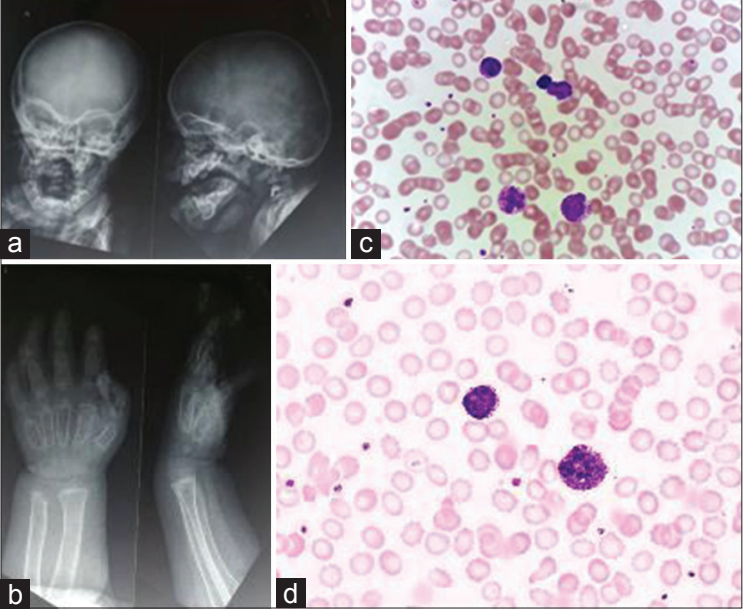

Figure 2: (a) The X-ray skull shows thickening of skull bones and "J-" shaped sella turcica. (b) Tapering of proximal metacarpals were found on the X-ray of Hands. ( $c$ and d) The photomicrograph shows neutrophils and lymphocytes showing Alder-Reilly anomaly. The Red blood cells series and platelets were morphologically unremarkable (Wright-Giemsa, ×1000)

SFL is based on lysing the cells and the binding of DNA/RNA/Bioactive proteins with polymethine based fluorescent dye. In this case, the flags were abnormal WBC scattergram, lymphocytosis which are clearly reflected on WNR and WDF scatter plots of the patient. The authors postulate that abnormal WBC scattergram in this patient was due to the internal granulations i.e. AR granules leading to abnormal SFL and SSC properties of all the leukocytes.

A trained eye review of peripheral smear substantiated the AR anomaly in the case. AR anomaly was first described by Alder in 1939 and later by Reilly in 1941, this leukocyte morphological anomaly was aptly named after them. ${ }^{[7]}$ It is characterized by the presence of large discrete azurophilic and basophilic granules in leukocytes. ${ }^{[2,3]}$ The granules may show a clear zone around them. The lysosomal enzymes which break down mucopolysaccharides are lacking which leads to accumulation of these dense granules in leukocytes and hence this leukocyte anamoly is associated with MPS. Furthermore, it has been reported rarely with myelodysplastic syndrome. ${ }^{[8]} \mathrm{AR}$ granules need to be differentiated from toxic granulations and ChediakHigashi granules. ${ }^{[9]}$ The toxic granules are seen in association with sepsis, toxic states, or growth factor therapy; and they can be differentiated from AR anomaly by the often presence of accompanying neutrophilia, immature myeloid cells, and absence of granules in lymphocytes. Chediak-Higashi is an immunodeficiency disorder showing the presence of granules in leukocytes which are larger and lesser in number compared to AR anomaly. The granules of the syndrome can also be seen in other leukocytes. AR neutrophils function normally whereas neutrophils of Chediak-Higashi are functionally 
defective and there is increased susceptibility to infections.

Different types of MPS are characterized by different types of enzyme deficiencies. ${ }^{[1-3]}$ Type IV MPS (Morquio syndrome) is AR disorder characterized by the deficiency of either $\beta$-galactosidase or Galactosamine-6-sulphatase and consequent deposition of keratan sulfate and chondroitin sulfate. It is pertinent to diagnose MPS at an early stage before there is end-organ damage. Specific enzyme replacement therapy and hematopoietic stem cell transplantation will form the cornerstone of treatment in such patients.

\section{Conclusion}

The manuscript highlights the association of AR anomaly and abnormal WBC scattergram in MPS; the judicial hematological assessment in proper clinical context can lead to the optimum diagnosis. These patients should further undergo chemical and genetic tests which represent the gold standard of diagnosis.

\section{Declaration of patient consent}

The authors certify that they have obtained all appropriate patient consent forms. In the form the patient(s) has / have given his/her/their consent for his/her/their images and other clinical information to be reported in the journal. The patients understand that their names and initials will not be published and due efforts will be made to conceal their identity, but anonymity cannot be guaranteed.

\section{Financial support and sponsorship} Nil.

\section{Conflicts of interest}

There are no conflicts of interest.

\section{References}

1. Neufeld EF, Muenzer J. The mucopolysaccharidoses. In: Scriver C, Beaudet AL, Valle D, Sly W, editors. The Metabolic and Molecular Bases of Inherited Disease. New York: McGraw-Hill; 2001. p. 3421.

2. AlMozain N, Bakshi NA. A case of hunter syndrome and Alder-Reilly anomaly. J Appl Hematol 2017;8:33-5.

3. Bhuyan P, Singh B, Chakrabarty S, Mohanty N, Agarwal M, Satpathy S, et al. Alder-Reilly anomaly in Hurler's syndrome in a neonate: A Rare case report. Indian J Hematol Blood Transfus 2013;29:184-6.

4. Sharma S, Sethi N, Pujani M, Kushwaha S, Sehgal S. Abnormal WBC scattergram: A clue to the diagnosis of malaria. Hematology 2013;18:101-5.

5. Gupta M, Chauhan K, Singhvi T, Kumari M, Grover RK. Useful information provided by graphic displays of automated cell counter in hematological malignancies. J Clin Lab Anal 2018;32:e22392.

6. Briggs C, Longair I, Kumar P, Singh D, Machin SJ. Performance evaluation of the sysmex haematology XN modular system. J Clin Pathol 2012;65:1024-30.

7. Straussberg R, Weitz R, Bessler H. A juvenile ceroid lipofuscinosis-like disease associated with Alder's anomaly: An ultrastructural study. Haema 1999;2:206-10.

8. Ghandi MK, Howard MR, Hamilton PJ. The Alder-Reilly anomaly in association with the myelodysplastic syndrome. Clin Lab Haematol 1996;18:39-40.

9. Bain BJ. Blood cell morphology in health and disease. In: Bain BJ Bates I, Laffan MA, Lewis SM, editors. Dacie and Lewis Practical Hematology. $11^{\text {th }}$ ed. China: Churchill Livingstone Elsevier; 2012. p. 90-2. 